\title{
1 Rheometry of Coarse Biomass at High Temperature and \\ Pressure
}

We designed, constructed, and tested a new device that can measure the rheological properties of lignocellulosic biomass slurries with high solids concentrations $(>25 \%)$ containing large particles $(>10 \mathrm{~mm})$, and that can operate at high temperatures $\left(>230^{\circ} \mathrm{C}\right)$, high pressures $(>2.8 \mathrm{MPa})$, and low $\mathrm{pH}(<1.0)$. Rheological properties measured with this Lignocellulosic Biomass Rheometer (LCBR) are consistent with those measured with another instrument. Biomass samples investigated are yield stress materials, consistent with previous reports. For modest temperatures, the viscosity decreases reversibly with increasing temperature. When the biomass is exposed to sufficiently high temperature and low $\mathrm{pH}$, we observe an irreversible decrease in apparent viscosity, consistent with that expected as hydrolysis reactions reduce the concentration of insoluble solids.

\footnotetext{
*Corresponding author

Email addresses: dan.klingenberg@wisc.edu (Daniel J. Klingenberg), twroot@wisc. edu (Thatcher W. Root), burlawar@wisc. edu (Shalaka Burlawar), tscottefs. fed.us (C. Tim Scott), kjbournedfs. fed.us (Keith J. Bourne), rgleisnerlfs.fed.us (Roland Gleisner), choutmanefs.fed.us (Carl Houtman), Vish.Subramaniameshell.com (Vish Subramaniam)
}

Preprint submitted to Elsevier

January 25, 2017 


\section{INTRODUCTION}

Lignocellulosic biomass processing typically involves numerous steps. In a process developed by the National Renewable Energy Laboratory (NREL) for the conversion of corn stover to ethanol $[1,2,3]$, the particle size of the biomass is first reduced, and then the biomass is pretreated using dilute-acid hydrolysis at elevated temperature to make the cellulose more accessible. This biomass is a suspension of natural fibers whose average fiber length starts at several centimeters to inches and decreases through subsequent processing steps. After pretreatment, the cellulose is then enzymatically hydrolyzed to produce glucose. The glucose is subsequently fermented to produce ethanol; the ethanol is then purified in separation steps. Ethanol from biomass has been a principal target fuel that is industrially relevant, but there are numerous proposed processing routes leading to other chemicals and fuels (e.g., hydrocarbons such as gasoline) $[3,4,5]$. Commercialization of such biorefining processes requires reducing the processing costs $[6,7,8]$.

Increasing the concentration of insoluble solids can reduce the cost of processing biomass $[9,10,11,12,13]$. Decreasing the water content reduces operating costs (e.g., heating, water handling) as well as capital costs. However, concentrated biomass suspensions are very viscous, non-Newtonian, complex fluids, which make mixing reactants and conveying the biomass challenging $[12,14,15$, $16,17,18,19]$. It is thus apparent that understanding their rheological properties is essential for designing efficient processes and equipment [13, 16, 20, 21, 22].

Measuring the yield stress and other rheological properties of lignocellulosic biomass in traditional rheometers can be challenging because of a variety of complicating factors, including large particle sizes, wall slip, large normal stresses, 
fracture, and ejection. These complications can be attributed to the diverse anatomical features of lignocellulosic biomass, including particle size and shape distributions, chemical composition variations, and compressibility. The advantages and disadvantages of a number of rheometric techniques used to obtain rheological data for acid-hydrolyzed corn stover were reported by Knutsen and Liberatore [21]. Nonetheless, numerous features of lignocellulosic biomass rheology are well established. Above a low mass fraction of solids, biomass suspensions are viscoplastic, shear thinning materials with a yield stress, $\tau_{0}$. The steady-state shear stress $(\tau)$ as a function of shear rate $(\dot{\gamma})$ has been represented by the Bingham $\left(\tau=\tau_{0}+\eta_{\mathrm{pl}} \dot{\gamma}\right)$, Casson $\left(\tau^{1 / 2}=\tau_{0}^{1 / 2}+\left(\eta_{\mathrm{pl}} \dot{\gamma}\right)^{1 / 2}\right)$, and Herschel-Bulkley models $\left(\tau=\tau_{0}+K \dot{\gamma}^{n}\right)[22,23,24,25,26,27]$. The yield stress of biomass is a rapidly increasing function of solids concentration, often represented by the empirical expression

$$
\tau_{0}=a C^{b}
$$

where $C$ is the solids concentration, and $a$ and $b$ are empirical parameters [28, 29, 30, 31]. The parameters depend on such properties as particle size distribution, fiber aspect ratio, stiffness, and additive type and concentration [27, 28, 29]. Values for $b$ vary from about 2.3 to 6 , and depend on the type of lignocellulosic biomass (e.g., wood pulp, corn stover, and acid-hydrolyzed corn stover) [21, 25, 28, 32].

The yield stress depends on a variety of other variables. Experimental [26, $28,29,33]$ and particle-level simulation studies [33, 34, 35] both show that the yield stress increases with increasing fiber length. Decreasing fiber stiffness leads to a decrease in fiber network shear strength [28, 36, 37]. The presence of various additives (e.g., rheological modifiers) can also modify the yield stress signifi- 
cantly $[27,38,39,40,41]$.

A critical element that is missing in our understanding of the rheological properties of biomass is the behavior of the biomass under the relatively extreme reaction conditions often employed in hydrolysis and other catalytic reactions (e.g., $170<T<230^{\circ} \mathrm{C}$ and low $\left.\mathrm{pH}\right)$. Furthermore, these properties change significantly during processing, so there is a great need to understand this behavior in situ while the reactions are proceeding. It is this information that is necessary for the design of practical processes for the efficient production of biofuels and other chemicals.

In this paper, we describe a new rheometer that is capable of measuring apparent rheological properties of lignocellulosic biomass at high temperatures ( $>$ $\left.230^{\circ} \mathrm{C}\right)$, high pressures $(>2.8 \mathrm{MPa})$, low $\mathrm{pH}(<1.0)$, very high solids concentrations, and for large particles $(>10 \mathrm{~mm})$. We show that rheological properties measured with this Lignocellulosic Biomass Rheometer (LCBR) are consistent with those measured with a torque rheometer. Biomass samples investigated show that these materials are yield stress fluids whose yield stress decreases with increasing temperature. Changes in apparent rheological properties with temperature are reversible at low temperatures, but apparent viscosities decrease dramatically and irreversibly at high temperatures, or when a sufficient amount of mineral acid is present. Irreversible changes in rheological properties appear to arise from the acid-catalyzed hydrolysis of the biomass solids.

\section{Materials and Methods}

\subsection{Equipment}

The Lignocellulosic Biomass Rheometer (LCBR) comprises an impeller and insert that are placed inside a 2 L Parr reactor (Model 4530, 2-liter Floor Stand 
Reactor, Parr Instrument Co., Moline, IL). The temperature of the reactor vessel is increased or decreased with an external heating/cooling jacket. The reactor head has ports for injecting liquids, inserting a thermocouple, pressure gauges (we do not report pressures in this paper), pressure relief devices. The impeller, insert, and Parr vessel and head (shown schematically in Fig. 1) are constructed from Hastelloy B2 and B3 alloys in order to resist corrosion under harsh reaction conditions (B2 was used for the Parr vessel and head, and B3 was used for the insert and impeller).

\section{(PLACE FIGURE 1 HERE)}

The impeller and insert were designed to allow for biomass with large particles and high solids concentrations to be well-mixed during hydrolysis reactions so that rheological properties can be measured. A photograph of the insert and impeller is shown in Fig. 2. The rheometer insert consists of a feed zone above a mixing zone. The feed zone was designed to provide sufficient pressure on the biomass to insure that the mixing zone is fully loaded during operation. The mixing zone has a capacity of $1 \mathrm{~L}$ and was designed to mix the biomass in a consistent, repeatable manner. The insert was made from a thin sheet $(31.000 \mathrm{~cm} \times 25.718$ $\mathrm{cm}$, with a thickness of $0.1588 \mathrm{~cm}$ ) of Hastelloy B3 that was drilled with pilot holes, and then rolled into a cylinder $(\mathrm{OD}=10.058 \mathrm{~cm})$ providing a clearance of $0.0508 \mathrm{~cm}$ to the inner diameter of the $2 \mathrm{~L}$ Parr vessel. Four windowed openings were cut out of the cylindrical insert to expose the sheared biomass to the Parr vessel wall for improved heat transfer.

(PLACE FIGURE 2 HERE) 
In the mixing zone (the space below the bottom of the guide bars), an array of static pins (also made from Hastelloy B3; $0.635 \mathrm{~cm}$ diameter, $3.810 \mathrm{~cm}$ long shouldered leaving a $0.152 \mathrm{~cm}$ stub) were welded into the pilot holes of the rolled cylinder at strategic locations to prevent the sheared biomass from rotating with the impeller as a rigid body. Four pins were placed in each of three horizontal planes to allow a sufficient gap $(0.953 \mathrm{~cm})$ for clearance of the rotating impeller.

In the feed zone (the space above the bottom of the guide bars), four vertical guide bars were welded onto the interior of the rolled cylinder for multiple purposes. Two of the guide bars incorporated locating pins $(0.635 \mathrm{~cm}$ diameter, $1.588 \mathrm{~cm}$ long) which were used to engage blind holes drilled into the Parr reactor head to keep the insert from rotating. A hole was drilled through one of the guide bars (Fig. 1) so that a thermowell attached to the Parr head could be inserted and protected from the rotating impeller and sheared biomass. The thermowell extends approximately $0.953 \mathrm{~cm}$ below the base of the guide bar into the mixing zone to measure the temperature of the biomass during operation. The guide bars also keep the weights (described below) from rotating.

The base of the LCBR insert was machined with a counter-bore recess for the placement of an impeller shaft centering/bearing pin. The lower end of the impeller shaft was bored and beveled to receive the pin and center the shaft.

The rotating shaft contains an array of blades that are pitched at a $30^{\circ}$ angle from horizontal and cut with a $1.905 \mathrm{~cm}$ radius on the leading and trailing edges. The top pair of blades is oriented to produce a downward flow of biomass from the feed zone into the mixing zone. The bottom pair of blades is oriented upward to scrape the biomass up off the insert base. The middle two tiers of blades are alternately pitched to cycle the biomass flow upward and downward (see Fig. 2). This 
blade configuration is designed to produce zero net motion of sheared material in the axial direction.

The shaft coupling was designed to combine a direct couple (threaded) to the Parr drive shaft and a snug-fit spline coupling to the LCBR impeller shaft such that the impeller shaft is not directly coupled to the Parr drive shaft and can be easily separated.

For most operating conditions, a weight is required to apply downward pressure on the biomass in the feed zone to keep the mixing zone fully packed. An optional spring-loaded system was designed to increase this downward pressure if needed. The spring was not used in the experiments reported here, and thus the normal force exerted on the biomass was limited by that of the weight $(1.326 \mathrm{~kg})$. Retention pins were placed as shown in Fig. 1 to limit the movement of the loading weight and restrict the displacement of the compression spring (made from coiled B3 welding wire). With a hole in the center, the weight also serves to center the impeller shaft for ease of coupling to the Parr drive shaft.

The insert and impeller were used in a Parr Model 4530, 2 L Floor Stand Reactor. Several modifications of the Parr reactor head were required to accommodate the insert and impeller shaft. Blind openings were drilled to receive the locating pins. The thermowell was reduced to $0.635 \mathrm{~cm}$ diameter and relocated inward on the same radius for insertion into the bore in the guide bar. The Parr drive shaft (internally coupled through the Mag Drive) was shortened to extend 1.613 $\mathrm{cm}$ below the surface of the reactor head, and was threaded $(1 / 2-20 \times 0.953 \mathrm{~cm})$ to receive the shaft coupling. Standard cooling ports were not used and were not provided. 
The LCBR reactor system is controlled by a Parr 4848B controller that has been modified. The 4848B controller as received from Parr has five modules that monitor and control the motor speed, reactor temperature, heater temperature, and pressure. The system also came with an MTM module that measured the voltage supplied to the motor controller by a signal isolator board. This module was not useful for measuring motor torque, and thus was repurposed as described below. These modules communicate via RS 485 serial communications with a PC with SpecView data logging software supplied by Parr. The SpecView software can control all of the settings on the 4848B controller remotely, as well as record and plot the data received from the modules (limited to a $1 \mathrm{~Hz}$ data acquisition rate). To measure the power consumed by the motor so that the shaft torque on the rheometer could be determined, an external power meter was built that measures the motor voltage with an NK Technologies (San Jose, CA) voltage transducer and the motor current with a CR Magnetics (St. Louis, MO) Hall effect current transducer. This power meter is plugged into the motor power cord between the $4848 \mathrm{~B}$ controller and the motor. The output of the voltage transducer is attached to the repurposed MTM module, and an additional module was added to the 4848B controller to measure the output from the current transducer. These modules are connected to the serial communications in the 4848B controller so that SpecView can read the voltage and current data in addition to the temperature, pressure, and speed data.

\subsubsection{Motor Torque Calibration}

The motor current is directly proportional to the torque delivered to the biomass. To determine the quantitative relationship between the motor current and torque, a Futek torque sensor (Irvine, CA, $50 \mathrm{Nm}$ capacity) was coupled to the Parr im- 
peller drive shaft. An independent A/D system utilizing LabView software was configured to acquire sensor signals. A large helical coupling was attached and manually restrained to provide variable torque resistance at selected motor speeds. The measured torque delivered through the Mag Drive $(\Gamma)$ is related to the motor current $(I)$ and impeller speed $(\Omega)$ by

$$
\Gamma=a I+b \Omega+c
$$

where $a=4.420 \pm 0.008 \mathrm{~N} \cdot \mathrm{m} \cdot \mathrm{A}^{-1}, b=-0.0638 \pm 0.0013 \mathrm{~N} \cdot \mathrm{m} \cdot \mathrm{s} \cdot \mathrm{rad}^{-1}$, and $c=-1.508 \pm 0.013 \mathrm{~N} \cdot \mathrm{m}$. Note that the torque is essentially a linear function of motor current and is only slightly affected by rotation speed. This is typical for the type of motor used in the Parr reactor (180 VDC, $0.75 \mathrm{hp}(559 \mathrm{~W})$ permanent magnet motor). The loss term $(-1.508 \mathrm{~N} \cdot \mathrm{m})$ was determined with the gear reducer running warm at steady state. (The torque predicted by Eq. 2 is plotted against the torque measured with the Futek torque transducer in Fig. S1 of the Supplementary Online Material.)

\subsubsection{Rheometer Operation}

First the impeller shaft is placed inside the insert with the bottom of the shaft engaged with the centering pin. The weight is then aligned with the guidebars and placed on the shaft to properly align it. The insert containing the impeller and weight is then placed in the cylindrical vessel. A "dry-fit" is first made to orient the impeller shaft, thermowell, and locating pins before biomass is added.

To load the mixing zone, the assembly is decoupled from the Parr head and the weight is removed. For the calibration described below, a high viscosity Newtonian fluid was heated and poured into the vessel. For comparison with measurements made with a torque rheometer, modeling clay was pushed into the mixing zone. For most experiments with biomass, a dry, granulated biomass is first 
poured into the mixing zone and lightly tamped. Once the mixing zone is filled, excess biomass is added in the feed zone and the weight is installed. Liquid (pure water or acid solution) is then added to obtain the desired $\mathrm{pH}$ and mass fraction of biomass solids (typically $20 \%$ ). Once the assembly is filled, it is recoupled to the Parr head for the start of a test. After a run, the vessel is cooled and any residual head pressure released. The vessel is then decoupled from the Parr head and placed in a sufficient containment receptacle. The LCBR insert can then be removed and the insoluble biomass and liquor recovered. The LCBR components can then be cleaned and re-assembled for the next test.

Apparent rheological properties measured using the LCBR were compared with those measured using a torque rheometer. The torque rheometer consists of two counter-rotating impellers within a chamber. The material is held within the chamber with a plunger that is held in place with a weight. Methods for measuring rheological properties of biomass with a torque rheometer are described in more detail elsewhere [22, 26].

\subsection{Materials}

The LCBR was calibrated using a standard Newtonian fluid (polybutene, Cannon). The viscosity values reported by Cannon at four different temperatures are plotted in Fig. 3 and tabulated in Table S1 of the Online Supplementary Material. To obtain "known" viscosities at other intermediate temperatures for calibration purposes, the tabulated viscosities were fit with the equation

$$
\eta(T)=A \exp \left(\frac{B}{T}\right),
$$

where $T$ is the absolute temperature. The best-fit parameter values are $A=$ $1.80237 \times 10^{-9} \mathrm{~Pa} \cdot \mathrm{s}$ and $B=7858.5 \mathrm{~K}$. The data are compared with the fit in Fig. 3. 
(PLACE FIGURE 3 HERE)

A modeling clay was used to compare rheological properties measured in the LCBR and a torque rheometer. The modeling clay was obtained from a local craft store (Polyform ModelAir manufactured by Polyform Products Company).

Corn plants were harvested in a forage/silage chopping operation using a John Deere Model 3950 Forage Harvester. The corn variety selected was Golden Harvest G05T82 (Syngenta) and was planted in mid-May, 2012. The harvest occurred in early October, 2012. The approximate growing location is in the northern re-

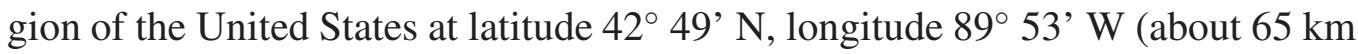
southwest of Madison, WI). In the harvesting operation, whole stalks (including ears) were severed $20-25 \mathrm{~cm}$ above the ground and chopped into particles approximately $2.5 \mathrm{~cm} \times 2.5 \mathrm{~cm}$. This material contains numerous particles with linear dimensions larger than $10 \mathbf{~ m m}$. The kernels remained relatively intact and were later manually removed. The remaining "corn stover" was subsequently air dried to approximately $8 \%$ moisture content and stored in sealed bags. For preliminary experiments, the corn stover was tested in this condition, specifically for comparing rheological properties measured with the LCBR and the torque rheometer. We will refer to this material as "chopped corn stover." However, the cob particles proved difficult to process so the corn stover was further size-reduced in a Wiley mill using a $5 \mathrm{~mm}$ screen and collected with a custom-designed vacuum collection system. This material is shown in Fig. 4, and was employed in other rheological experiments. We refer to this material as "chopped and milled corn stover."

A second supply of corn stover was obtained by manually harvesting corn plants (Northrup King N45P, planted in mid-May of 2016 and harvested in 
October of 2016 at latitude $42^{\circ} 49^{\prime} \mathrm{N}$, longitude $89^{\circ} 53$ ' $\mathrm{W}$, about 65 miles southwest of Madison, Wisconsin), removing the kernel and hammermilling the rest of the harvested plants. The hammermilled material was further size-reduced in a Wiley mill using a $3 \mathrm{~mm}$ screen and air dried. The moisture content was approximately $5 \%$. We refer to this material as "milled corn stover," which was also used to compare rheological properties measured with the LCBR and the torque rheometer.

(PLACE FIGURE 4 HERE)

\section{Results}

\subsection{Calibration}

Torque-rotation rate data can be converted to conventional rheological quantities using a calibration procedure that involves representing the actual geometry with an idealized geometry. Torque-rotation rate data obtained for fluids with known rheological properties can then be used to determine the dimensions of the idealized geometry. Such a calibration for the idealized geometry of concentric cylinders is shown below (and illustrated in Fig. S2 of the Online Supplementary Material). A calibration employing an idealized geometry of parallel disks leads to essentially equivalent results, as described in the Online Supplementary Material.

Here we describe a calibration approach analogous to that developed for torque rheometers by Goodrich and Porter [42], where the rheometer is represented by a set of concentric cylinders (as illustrated in Fig. S2). The outer cylinder radius, $R_{o}$, is equated with the insert inner radius. The effective inner radius, $R_{i}$, is determined by equating the measured torque for a Newtonian fluid with 
known viscosity with that calculated from the solution of the Navier-Stokes equation [43]. Bousmina et al. [44] showed that such a calibration with a Newtonian fluid gives equivalent results to those obtained using a more sophisticated analysis with power-law fluids.

The torque $(\Gamma)$ and rotation rate $(\Omega)$ for tangential flow between concentric cylinders are related to the apparent shear stress $\left(\tau_{\text {app }}\right)$ and apparent shear rate $\left(\dot{\gamma}_{\text {app }}\right)$ via

$$
\tau_{\text {app }}=K_{\tau} \Gamma,
$$

$$
\dot{\gamma}_{\text {app }}=K_{\dot{\gamma}} \Omega \text {, }
$$

where

$$
K_{\tau}=\frac{1}{2 \pi R_{i}^{2} h},
$$

$$
K_{\dot{\gamma}}=\frac{2 R_{i} R_{o}}{\left(\frac{1}{\kappa}-\kappa\right)} \frac{1}{R_{a}^{2}},
$$

and where $R_{a} \equiv\left(R_{i}+R_{o}\right) / 2$ is the midpoint radius, $h$ is the impeller height, and $\kappa \equiv R_{i} / R_{o}$. This approach is consistent with that employed in commercial rheometers [45]. Note that Eq. 6 is obtained from a momentum balance that is valid for any type of fluid, whereas Eq. 7 is obtained from the equation of motion for incompressible Newtonian fluids, and thus is only strictly valid for Newtonian fluids.

To calibrate the rheometer, we note that the ratio of Eqs. 4 and 5 gives

$$
\frac{\tau_{\text {app }}}{\dot{\gamma}_{\text {app }}} \equiv \eta_{\text {app }}=\left[\frac{\left(1-\left(R_{i} / R_{o}\right)^{2}\right) R_{a}^{2}}{4 \pi R_{i}^{4} h}\right] \frac{\Gamma}{\Omega}
$$

where $\eta_{\text {app }}$ is the apparent viscosity of the material in the rheometer. Thus a plot of $\eta \Omega$ vs. $\Gamma$ for a Newtonian fluid with known viscosity $\eta$ should yield a straight 
line with a slope given by the quantity in square brackets in Eq. 8; from this slope, one can extract the effective inner radius $R_{i}$.

The calibration experiments were performed by first heating the polybutene in the Parr cylinder to above $60^{\circ} \mathrm{C}$. The fluid was allowed to cool slowly within the LCBR. At several temperatures, the torque was measured for a variety of rotation rates. For each rotation rate, the data were collected over $50 \mathrm{~s}$ (1 Hz acquisition rate), and then averaged. This provided data for $\Gamma$ as a function of $\Omega$ for each temperature. For each temperature, the viscosity $\eta(T)$ is known via Eq. 3, and thus we are able to construct a set of data for $\Omega \eta$ as a function of $\Gamma$. The results are presented in Fig. S3 of the Online Supplementary Material, where $\Omega \eta$ is plotted as a function $\Gamma$. The slope obtained from a least-squares fit of the data to a straight line passing through the origin is $\mathbf{1 7 3} \pm \mathbf{5} \mathbf{~ m}^{-3}$. The value of $R_{i}$ obtained by equating the slope with the term in square brackets in Eq. 8 (using $R_{o}=0.04864 \mathrm{~m}$ and $h=0.141 \mathrm{~m}$ ) is $R_{i}=0.038790 \pm 0.00018 \mathrm{~m}$ (or $\left.\kappa=R_{i} / R_{o}=\mathbf{0 . 7 9 8} \pm \mathbf{0 . 0 0 4}\right)$.

Once the effective inner radius is known, torque-rotation rate data can be converted to apparent shear stress-shear rate data using Eqs. 4 and 5. Using the value of $R_{i}$ determined from the calibration, as well as the known values of $R_{o}$ and $h$ specified above, we obtain the values of $K_{\tau}$ and $K_{\dot{\gamma}}$ from Eqs. 6 and 7 as

$$
K_{\tau}=750 \pm 7 \mathrm{~m}^{-3}
$$

$$
K_{\dot{\gamma}}=4.33 \pm 0.09 \mathrm{rad}^{-1}
$$

\subsection{Modeling the Torque-Rotation Rate Data}

Torque-rotation data can also be fit with a convenient rheological model to obtain model parameters. For biomass, we have fit such data with the Bingham 
model. For flow of a Bingham fluid between concentric cylinders, the relationship between torque and rotation rate is

$$
\Gamma=4 \pi R_{i}^{2} h \eta_{\mathrm{pl}}\left[\frac{\Omega+\frac{\tau_{0}}{\eta_{\mathrm{pl}}} \ln \left(\frac{r_{0}}{R_{i}}\right)}{1-\frac{R_{i}^{2}}{r_{0}^{2}}}\right]
$$

where $\tau_{0}$ is the yield stress, $\eta_{\mathrm{pl}}$ is the plastic viscosity, and $r_{0}$ is the yield surface, which is the minimum of $R_{o}$ and the solution to equation

$$
\left(\frac{r_{0}}{R_{i}}\right)^{2}-1=\frac{2 \eta_{\mathrm{pl}} \Omega_{k}}{\tau_{0}}+\ln \left[\left(\frac{r_{0}}{R_{i}}\right)^{2}\right] .
$$

Torque-rotation data obtained with the LCBR were fit with Eq. 11 to obtain yield stresses and plastic viscosities. When the plastic viscosity is positive, the fit is performed with a nonlinear, least-squares algorithm. When the plastic viscosity is negative, the torque is simply fit as a linear function of rotation rate, with the $y$ intercept equated with $2 \pi R^{2} h \tau_{0}$.

\subsection{Modeling Clay}

Apparent rheological properties of modeling clay were measured at $65^{\circ} \mathrm{C}$ using both the LCBR and the torque rheometer. Data obtained using the LCBR were acquired at $1 \mathrm{~Hz}$, and data obtained with the torque rheometer were acquired at 5 $\mathrm{Hz}$; all data were averaged over at least $100 \mathrm{~s}$. The data are presented in Fig. 5. The apparent viscosity is plotted as a function of apparent shear rate for both apparatuses in Fig. 5(a). The two rheometers accessed different shear rate ranges, but the two sets of data are consistent with nearly identical viscosities in the region where the shear rate ranges overlap. The inset shows the viscosity plotted as a function of shear stress. The data fall on a nearly vertical line, consistent with a yield stress material. The shear stress is plotted as a function of shear 
rate in Fig. 5(b). The apparent nonzero intercept illustrates the existence of a yield stress, which is similar for the two data sets. The data are replotted in the inset with the shear rate on a $\log$ scale. Here the yield stress appears as a plateau at low shear rates.

\section{(PLACE FIGURE 5 HERE)}

The flow behavior of the modeling clay in the LCBR was investigated at the end of the test. The LCBR insert containing the clay and the impeller were removed from the $2 \mathrm{~L}$ vessel. The impeller blade ends travel close to the insert radius, leaving only a small amount of clay beyond the end the impeller. A pick was used to remove this small amount of clay to expose an impeller blade, which revealed a cavity behind the impeller blade (Fig. 6). Such a situation is expected when an object translates through a Bingham plastic material, "carving" a channel along its path. More importantly, however, the space in front of the impeller blade is completely filled with clay. The absence of a cavity in front of the advancing impeller blade arises because an impeller blade below the one in question is pitched so that it will push material into the cavity created by the first blade. In fact, the pitches of all of the blades were designed to push material into all cavities created by blades above or below. This feature is essential to the operation of the device as a rheometer. If the cavities were not filled but became permanent during the impeller rotation, the material would exert no torque on the impeller. Designing appropriate pitches on the blades creates only temporary cavities, and thus allows the material to exert a torque on the impeller at all times.

(PLACE FIGURE 6 HERE) 


\subsection{Lignocellulosic biomass}

Rheological properties of chopped corn stover suspensions, as well as milled corn stover suspensions, were measured using both the LCBR and the torque rheometer. For the chopped corn stover, only one sample was examined in each rheometer at an insoluble solids mass fraction of $15 \%$. The material was loaded into each rheometer, and properties at several apparent shear rates were measured at room temperature. For the milled corn stover, three replicate runs were performed at each shear rate-that is, between replicate runs, the rheometers were emptied and then reloaded with new biomass from the same source and at the same concentration (insoluble mass fraction $=20 \%$ ). In each experiment, the temperature was first increased to $90^{\circ} \mathrm{C}$, then decreased to $33.0 \pm 0.5^{\circ} \mathrm{C}$, while shearing at moderate rotation rate the entire time. Data were then collected at various apparent shear rates. For the LCBR, data were collected for $60 \mathrm{~s}$ at each rotation rate and averaged. For the torque rheometer, data were collected for $100 \mathrm{~s}$ at each rotation rate and averaged. For each rheometer, the averages from the replicate runs were used to obtain overall averages and uncertainties. The results for both materials are presented in several ways in Fig. 7. In Fig. 7(a), the apparent viscosity is plotted as a function of apparent shear rate, with the apparent viscosity plotted as a function of shear stress in the inset. The data from the two rheometers agree qualitatively for both stover materials, with a pronounced shear thinning viscosity as the shear rate is increased. The apparent viscosities obtained with the torque rheometer are larger than those obtained with the LCBR. The slope of the log-log plot of apparent viscosity vs apparent shear rate is approximately -1 , indicative of fluids with a yield 
stress. When the apparent viscosity is plotted as a function of apparent shear stress (inset), the data illustrate a rapid change of viscosity with shear rate, as expected for yield stress materials with stresses near the yield stress. In Fig. 7(b) we have plotted the apparent shear stress as a function of apparent shear rate. For the torque rheometer, the apparent shear stress decreases with increasing shear rate. Such negative plastic viscosities have been reported previously for suspensions of untreated lignocellulosic biomass near room temperature [27]. For the LCBR, the chopped corn stover also exhibits a decrease in stress with increasing shear rate. For the milled stover, linear regression also gives a negative slope, but the magnitude of the slope is smaller than the uncertainty (slope $=-7 \pm 14 \mathbf{P a} \cdot \mathbf{s}$ ). A negative slope may become more pronounced if a wider range of rotation rates were employed.

\section{(PLACE FIGURE 7 HERE)}

The mechanisms that produce a negative plastic viscosity, and the conditions for which they are observed are unclear (except that we do not observe negative plastic viscosities for measurements with clay or Newtonian fluids). Further investigation and discussion of negative plastic viscosities is the subject of future work.

While the rheological data for lignocellulosic biomass suspensions measured with the LCBR and torque rheometer agree qualitatively, the quantitative agreement is not as good as for the data obtained for modeling clay. We note that the stresses measured for lignocellulosic biomass on different instruments can differ by more than a factor of two, with stresses measured using the torque rheometer typically larger than those measured with other devices [22]. 
Typical raw data for chopped and milled corn stover (insoluble solids mass fraction $=20 \%$, without acid) are presented in Fig. 8, where the torque, rotation rate, and temperature are plotted as a function of time. There are several noteworthy features of the temperature dependence of the rheological behavior of the biomass. First, the torque (and thus apparent shear stress and viscosity) decrease significantly as the temperature is increased to $155^{\circ} \mathrm{C}$. Second, the temperature dependence is largely reversible under these conditions (i.e., maximum temperature $\leq 155^{\circ} \mathrm{C}$, no added acid)-the torque increases again as the temperature is subsequently decreased. Third, the torque fluctuates, but the fluctuations decrease significantly as the temperature is increased. The fluctuations then increase when the temperature is subsequently decreased.

Most of the data in Fig. 8 were obtained for a rotation rate of $1.57 \mathrm{rad} \cdot \mathrm{s}^{-1}$. At certain times, the rotation rate was cycled to $4.71,9.42,4.71$, and back to 1.57 $\mathrm{rad} \cdot \mathrm{s}^{-1}$. The duration of each intermediate rotation rate step was $50 \mathrm{~s}$. For temperatures above approximately $80^{\circ} \mathrm{C}$, the torque tends to increase as the rotation rate is increased.

\section{(PLACE FIGURE 8 HERE)}

The torque values obtained during each of the rotation rate steps were averaged over the $50 \mathrm{~s}$ steps. The average torque and rotation rate values obtained during the first four rotation rate cycles in Fig. 8 were converted to apparent shear stress and apparent shear rate using Eqs. 4 and 5, and these transformed data are presented in Fig. 9. The symbols represent the experimental data, and the solid curves represent fits of the torque-rotation rate data with the Bingham model (Eq. 11), with 
results converted to stress as a function of shear rate using Eqs. 4 and 5. The values of the best fit parameters (the yield stress and plastic viscosity) at the different temperatures are tabulated in Table 1. The data are well described by the Bingham model as commonly observed for biomass and other suspensions of synthetic and natural fibers $[22,23,24,25,26,27]$. Figure 9 also illustrates that the stresses decrease with increasing temperature.

\section{(PLACE FIGURE 9 HERE)}

The effect of sulfuric acid on the rheological properties of biomass are illustrated in Fig. 10, where the apparent viscosity is plotted as a function of temperature for a single sample of corn stover (insoluble solids mass fraction $=20 \%$ ) with $1.0 \% \mathrm{H}_{2} \mathrm{SO}_{4}$. The first data point at $55^{\circ} \mathrm{C}$ shows that the viscosity is large, consistent with previous data. As the temperature is increased, the viscosity decreases. The heating rate was $6^{\circ} \mathrm{C} / \mathrm{min}$ for the first two data points, and then reduced to less than $1^{\circ} \mathrm{C} / \mathrm{min}$. When the temperature reached $166^{\circ} \mathrm{C}$, the $\mathrm{LCBR}$ was then cooled (cooling rate less than $1^{\circ} \mathbf{C} / \mathbf{m i n}$ ). In this case, the viscosity subsequently remained small, much less than that measured before the sample was heated to $166^{\circ} \mathrm{C}$. Visual inspection of the biomass after the experiment revealed that the biomass solids average particle size and overall concentration had decreased significantly because of the acid-catalyzed hydrolysis of the solids. The conditions that produce reversible and irreversible rheological changes with increased temperature, and the associated changes in other material properties, will be discussed further in a future publication.

(PLACE FIGURE 10 HERE) 


\section{CONCLUSIONS}

In this report, we have demonstrated that the LCBR is capable of measuring apparent rheological properties that are consistent with those measured with another instrument. The range of torques accessible are appropriate for investigating the rheology of concentrated lignocellulosic biomass. The device is capable of measuring properties at high temperature, high pressure, low $\mathrm{pH}$, and high solids concentrations. The impeller design provides sufficient mixing to measure rheological properties as a function of time.

Preliminary tests reveal a number of interesting phenomena. Changing the temperature results in dramatic changes in the apparent suspension viscosity. When the temperature remains below approximately $150^{\circ} \mathrm{C}$ (no acid added), the apparent viscosity decreases reversibly with increasing temperature. In the presence of sulfuric acid, rheological changes are irreversible as the biomass is hydrolyzed. There are temporal torque fluctuations whose magnitude tends to decrease with increasing temperature.

Some conditions produced a negative plastic viscosity, that is, a decrease in apparent shear stress with an increase in apparent shear rate. This phenomenon was observed in both rheometers, and has been reported previously for biomass suspensions [27]. The existence of a negative plastic viscosity appears to depend on particle size, concentration, and temperature, and perhaps other variables. The mechanisms that produce this behavior are unclear, and will be discussed further in future publications. 
483

484

\section{ACKNOWLEDGEMENTS}

We acknowledge the following individuals for assistance with this project:

Dave Eustice, Chester Filipowics, Rick Reiner, Jennie Berglund, and undergraduate students Ben Dolata, Collin Schmidt, Cassie Perttula, and Adam Heder. This work was supported in part by Shell Global Solutions, and the U.S. Department of Agriculture (AFRI award number 2010-65504-20406). 


\section{REFERENCES}

\section{References}

[1] A. Aden, M. Ruth, K. Ibsen, J. Jechura, K. Neeves, J. Sheehan, B. Wallace, L. Montague, A. Slayton, J. Lukas, Lignocellulosic biomass to ethanol process design and economics utilizing co-current dilute acid prehydrolysis and enzymatic hydrolysis for corn stover, NREL Technical Report TR-51032438, 2002.

[2] D.J. Schell, J. Farmer, M. Newman, J. D. McMillan JD, Dilute-sulfuric acid pretreatment of corn stover in pilot-scale reactor. Investigation of yields, kinetics, and enzymatic digestibilities of solids, Appl. Biochem. Biotechnol. 105 (2003) 69-85.

[3] R. Davis, L. Tao, C. Scarlata, E.C.D. Tan, J. Ross, J. Lukas, and D. Sexton, Process design and economics for the conversion of lignocellulosic biomass to hydrocarbons: Dilute-acid and enzymatic deconstruction of biomass to sugars and catalytic conversion of sugars to hydrocarbons, NREL Technical Report NREL/TP-5100-62498, March 2015.

[4] G. Huber G (ed.), Breaking the Chemical and Engineering Barriers to Lignocellulosic Biofuels: Next Generation Hydrocarbon Biorefineries. Washington D.C.: National Science Foundation, Chemical Bioengineering, Environmental, and Transport Systems Division, 2008.

[5] S.G. Wettstein, D.M. Alonso, Y. Chong, J.A. Dumesic, Production of levulinic acid and gamma-valerolactone (GVL) from cellulose using GVL as a solvent in biphasic systems, Energy Environ. Sci. 5 (2012) 8199-8203. 
[6] R. Wooley, M. Ruth, J. Sheehan, K. Ibsen, H. Majdeski, A. Galvez, Lignocellulosic biomass to ethanol process design and economics utilizing cocurrent dilute acid prehydrolysis and enzymatic hydrolysis current and futuristic scenarios. NREL Technical Report TP-580-26157, 1999.

[7] J. Sheehan, A. Aden, K. Paustian, K. Killian, J. Brenner, M. Walsh M, R. Nelson, Energy and environmental aspects of using corn stover for fuel ethanol, J. Ind. Ecology 7 (2004) 117-146.

[8] C.E. Wyman, What is (and is not) vital to advancing cellulosic ethanol, Trends in Biotechnology 25 (2007) 153-157.

[9] L.R. Lynd, Overview and evaluation of fuel ethanol from cellulosic biomass: Technology, economics, the environment, and policy, Annu. Rev. Energy Environ. 21 (1996) 403-465.

[10] A. Wingren, M. Galbe, G. Zacchi, Techno-economic evaluation of producing ethanol from softwood: Comparison of SSF and SHF and identification of bottlenecks, Biotechnol. Prog. 19 (2003) 1109-1117.

[11] H. Jorgensen, J. Vibe-Pedersen, J. Larsen, C. Felby, Liquefaction of lignocellulose at high-solids concentrations, Biotechnol. Bioeng. 96 (2007) 862870.

[12] D.B. Hodge, M.N. Karim, D.J. Schell, J.D. McMillan, Model-based fed-batch for high-solids enzymatic cellulose hydrolysis, Appl. Biochem. Biotechnol. 152 (2009) 88-107. 
[13] C.M. Roche, C.J. Dibble, J.S. Knutsen, J.J. Stickel, M.W. Liberatore, Particle concentration and yield stress of biomass slurries during enzymatic hydrolysis at high-solids loadings, Biotechnol. Bioeng. 104 (2009) 290-300.

[14] L. Rosgaard, P. Andric, K. Dam-Johansen, S. Pedersen, A.S. Meyer, Effects of substrate loading on enzymatic hydrolysis and viscosity of pretreated barley straw, Appl. Biochem. Biotechnol. 143 (2007) 27-40.

[15] B. Um, T.R. Hanley, A comparison of simple rheological parameters and simulation data for zymomonas mobilis fermentation broths with high substrate loading in a 3-L bioreactor, Appl. Biochem. Biotechnol. 145 (2008) $29-38$.

[16] S. Viamajala, J.D. McMillan, D.J. Schell, R.T. Elander RT, Rheology of corn stover slurries at high solids concentrations, Effects of saccharification and particle size, Bioresource Technology 100 (2009) 925-934.

[17] Y. Lu, Y. Wang, G. Xu, J. Chu, Y. Zhuang, S. Zhang, Influence of high solid concentration on enzymatic hydrolysis and fermentation of steam-exploded corn stover biomass, Appl. Biochem. Biotechnol. 160 (2010) 360-369.

[18] M. Vaezi, A. Kumar, Pipeline hydraulic transport of biomass materials: A review of experimental programs, empirical correlations, and economic assessments, Biomass and Bioenerg. 81 (2015) 70-82.

[19] N.C. Crawford, N. Nagle, D.A. Sievers, J.J. Stickel, The effects of physical and chemical preprocessing on the flowability of corn stover, Biomass and Bioenerg. 85 (2016) 126-134. 
[20] N. Pimenova, T. Hanley, Measurement of rheological properties of corn stover suspensions, Appl. Biochem. Biotechnol. 106 (2003) 383-392.

[21] J.S. Knutsen, M.W. Liberatore, Rheology of high-solids biomass slurries for biorefinery applications, J. Rheol. 53 (2009) 877-892.

[22] J.J. Stickel, J.S. Knutsen, M.W. Liberatore, W. Luu, D.W. Bousfield, D.J. Klingenberg, C.T. Scott, T.W. Root, M. Ehrhardt, T.O. Monz, Rheology measurements of a biomass slurry: an inter-laboratory study, Rheol. Acta 48 (2009) 1005-1015.

[23] W.C. Chase, A.A. Donatelli, J.W. Walkinshaw, Effects of freeness and consistency on the viscosity of hardwood and softwood pulp suspensions, Tappi Journal 72 (1989) 199-204.

[24] N. Pimenova, T. Hanley, Effect of corn stover concentration on rheological characteristics, Appl. Biochem. Biotechnol. 114 (2004) 347-360.

[25] M.R. Ehrhardt, T.O. Monz, T.W. Root, R.K. Connelly, C.T. Scott, D.J. Klingenberg, Rheology of dilute acid hydrolyzed corn stover at high solids concentration, Appl. Biochem. Biotech. 160 (2010) 1102-1115.

[26] J.R. Samaniuk, J. Wang, T.W. Root, C.T. Scott, D.J. Klingenberg, Rheology of concentrated biomass, Korea-Australia Rheol. J. 23 (2011) 237-245.

[27] J.R. Samaniuk, C.T. Scott, T.W. Root, D.J. Klingenberg, Rheological modification of corn stover biomass at high solids concentrations, J. Rheol. 56 (2012) 649-665. 
[28] C.P.J. Bennington, R.J. Kerekes, J.R. Grace, The yield stress of fibre suspensions, Can. J. Chem. Eng. 68 (1990) 748-757.

[29] B. Dalpke, R. Kerekes, The influence of fibre properties on the apparent yield stress of flocculated pulp suspensions, J. Pulp Paper Sci. 31 (2005) 39-43.

[30] R.J. Kerekes, R.M. Soszynski, P.A. Tam Doo, The flocculation of pulp fibres, in: V. Punton (ed.) Papermaking Raw Materials, Transactions of the Eighth Fundamental Research Symposium London, Mechanical Engineering Publications Limited, pp. 265-310, 1985.

[31] R. Kerekes, Rheology of fibre suspensions in papermaking: An overview of recent research, Nordic Pulp Paper Res. J. 21 (2006) 598-612.

[32] B. Derakhshandeh, S.G. Hatzikiriakos, C.P.J. Bennington, The apparent yield stress of pulp fiber suspensions, J. Rheol. 54 (2010) 1137-1154.

[33] J.R. Samaniuk, C.T. Scott, T.W. Root, D.J. Klingenberg, The effect of high intensity mixing on the enzymatic hydrolysis of concentrated cellulose fiber suspensions, Bioresource Technology 102 (2011) 4489-4494.

[34] L.H. Switzer LH, D.J. Klingenberg, Rheology of sheared flexible fiber suspensions via fiber-level simulations, J. Rheol. 47 (2003) 759-778.

[35] J. Wang, Ph.D. Thesis, University of Wisconsin, 2013.

[36] J. Bergman, N. Takamura, The correlation between the shear modulus of fibre networks and the individual fibre stiffness, Svensk Papperstidn. 68 (1965) 703-710. 
[37] K.E. Almin, P. Biel, D. Wahren, Relating the shear modulus of fibre networks to the bulk average fiber stiffness, Svensk Papperstidn. 70 (1967) $772-774$.

[38] S. Zauscher, C.T. Scott, J.L. Willett, D.J. Klingenberg, Pulp extrusion for recycling wastepapers and paper mill sludges, TAPPI J., 83 (2000) 62.

[39] S. Zauscher, Ph.D. Thesis, University of Wisconsin, 2000.

[40] J.S. Knutsen, M.W. Liberatore, Rheology modification and enzyme kinetics of high solids cellulosic slurries, Energy Fuels 24 (2010) 3267-3274.

[41] J.R. Samaniuk, Ph.D. Thesis, University of Wisconsin, 2012.

[42] J.E. Goodrich, R.S. Porter, A rheological interpretation of torque-rheometer data, Polym. Sci. Eng. 7 (1967) 45-51.

[43] M.R. Ehrhardt, M.S. Thesis, University of Wisconsin, 2008.

[44] M. Bousmina, A. Ait-Kadi, J.B. Faisant, Determination of shear rate and viscosity from batch mixer data, J. Rheol. 43 (1999) 415-433.

[45] Bohlin VOR Rheometer Users Manual, Malvern Instruments, Westborough, MA. 
Table 1: Best fit Bingham model parameters for the data presented in Fig. 9. Uncertainties are only estimated for data sets with three or more data points.

\begin{tabular}{ccc}
\hline$T$ & $\tau_{0}$ & $\eta_{\mathrm{pl}}$ \\
$\left({ }^{\circ} \mathrm{C}\right)$ & $(\mathrm{Pa})$ & $(\mathrm{Pa} \cdot \mathrm{s})$ \\
\hline 95 & 1940 & 19 \\
125 & 1400 & 14 \\
140 & $900 \pm 200$ & $12 \pm 8$ \\
150 & $510 \pm 30$ & $16 \pm 2$ \\
\hline
\end{tabular}




\section{FIGURE CAPTIONS}

Figure 1: Schematic diagram of the Lignocellulosic Biomass Rheometer (LCBR).

Figure 2: Photograph of the LCBR insert and impeller, designed to fit in a $2 \mathrm{~L}$ Parr reactor. Left: the cylindrical insert with interior static pin array. Right: the bladed impeller shaft with the slotted weight and Parr shaft coupling.

Figure 3: Viscosity as a function of temperature for the standard Newtonian fluid (polybutene) obtained from Cannon, along with the fit with Eq. 3.

Figure 4: (a) Chopped corn stover. (b) Chopped and milled corn stover (bar $=2.54 \mathrm{~cm}$ ).

Figure 5: (a) Apparent viscosity as a function of apparent shear rate for modeling clay measured with the LCBR and the torque rheometer at $65^{\circ} \mathrm{C}$. Inset: Apparent viscosity as a function of shear stress. (b) Apparent shear stress as a function of apparent shear rate. Inset: Apparent shear stress as a function of apparent shear rate on a log scale. Error bars are smaller than the symbols.

Figure 6: Photograph of the clay following the LCBR operation. The exposed impeller blade was moving right to left. A cavity is apparent behind the blade. The space in front of the blade is filled with clay because an impeller blade below (not visible) pushed material into the previously formed cavity. 
Figure 7: (a) Apparent viscosity as a function of apparent shear rate for chopped corn stover (insoluble solids mass fraction $=15 \%$ ) and milled corn stover (insoluble solids mass fraction $=20 \%$ ) measured using the LCBR and the torque rheometer (TR). Inset: Apparent viscosity as a function of apparent shear stress (b) Apparent shear stress as a function of apparent shear rate. Inset: Apparent shear stress as a function of apparent shear rate on a log scale.

Figure 8: Raw data obtained using the LCBR with chopped and milled corn stover (insoluble solids mass fraction $=20 \%$ ) without acid.

Figure 9: (a) Apparent viscosity as a function of apparent shear rate at different temperatures for chopped and milled corn stover (insoluble solids mass fraction $=20 \%$ ) without acid, as the biomass is heated from 95 to $150^{\circ} \mathrm{C}$. The solid curves are fits with the Bingham model. (b) Apparent shear stress as a function of apparent shear rate. The error bars are smaller than the symbols.

Figure 10: Apparent viscosity vs. temperature for chopped and milled corn stover (insoluble solids mass fraction $=20 \%)$ with acid $\left(1.0 \% \mathrm{H}_{2} \mathrm{SO}_{4}\right)$. 


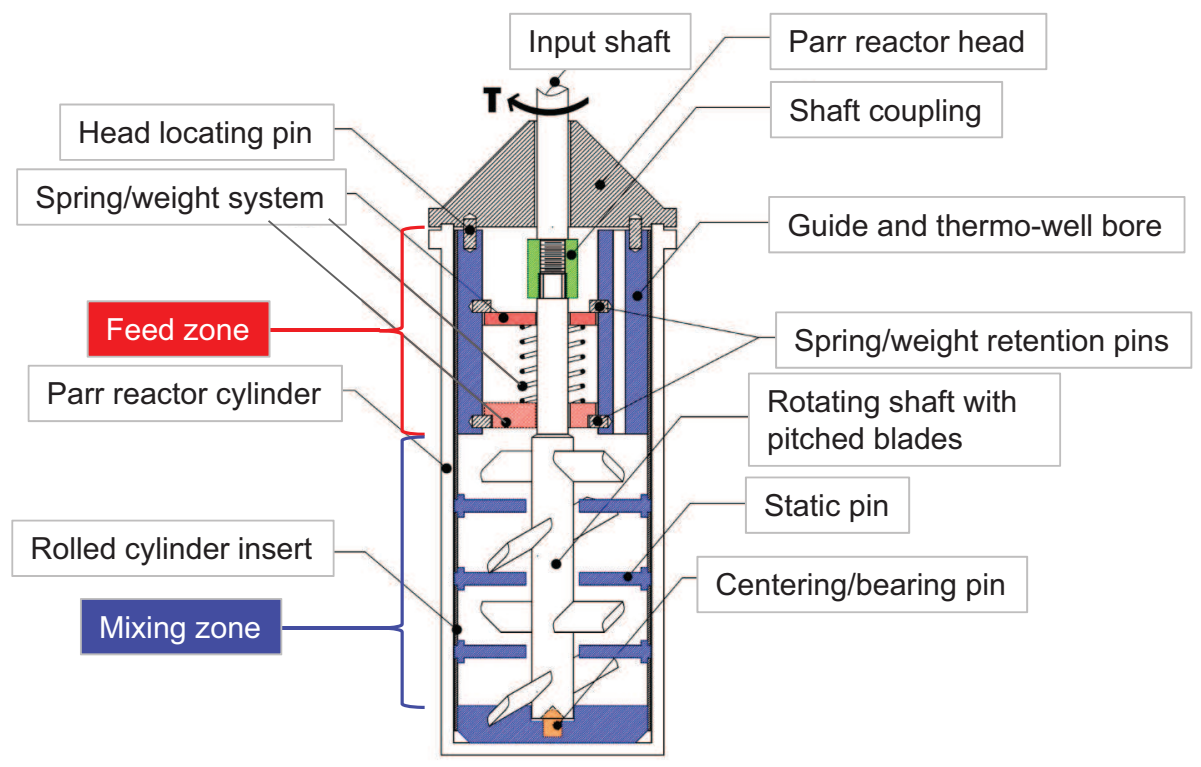

Figure: 1

Author: Klingenberg

Journal: Biomass and Bioenergy 


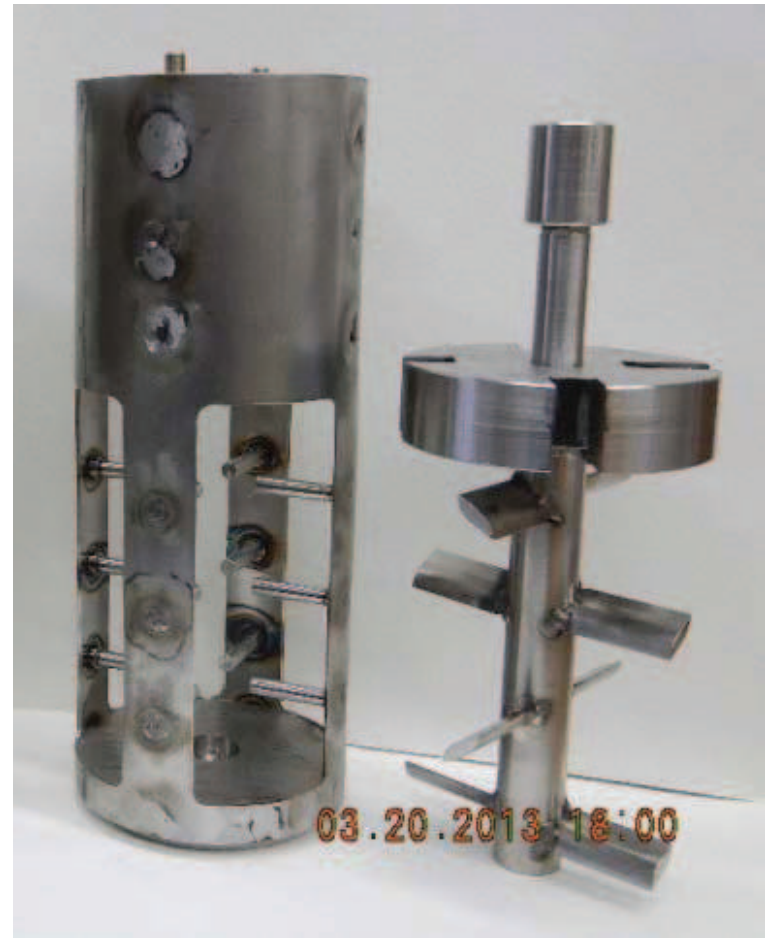

Figure: 2

Author: Klingenberg

Journal: Biomass and Bioenergy 


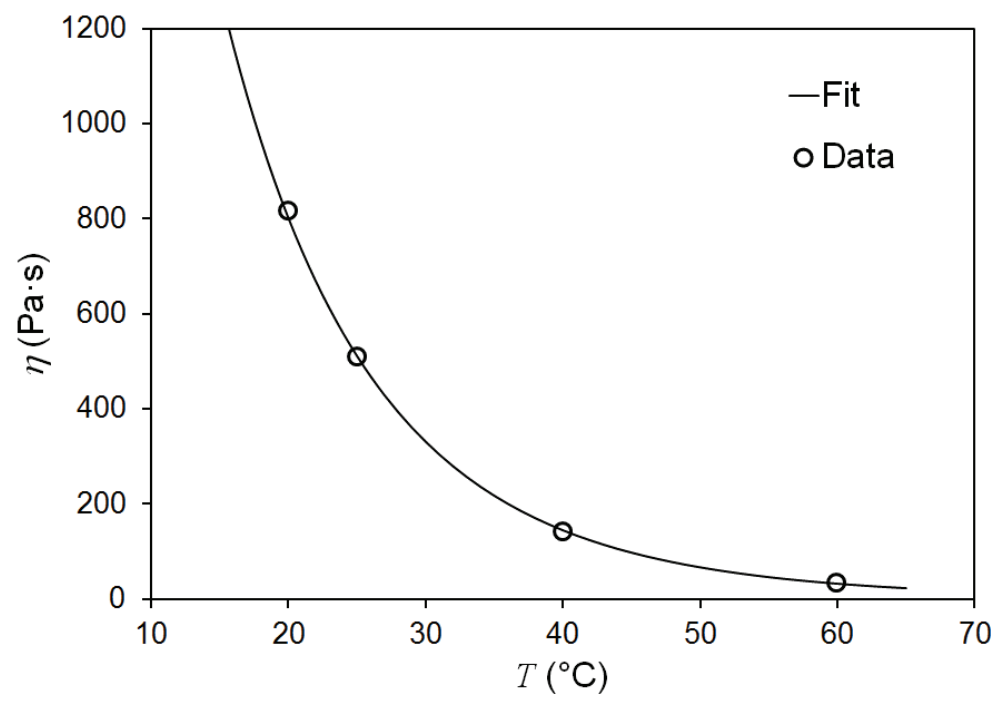

616

Figure: $\quad 3$

Author: Klingenberg

Journal: Biomass and Bioenergy 


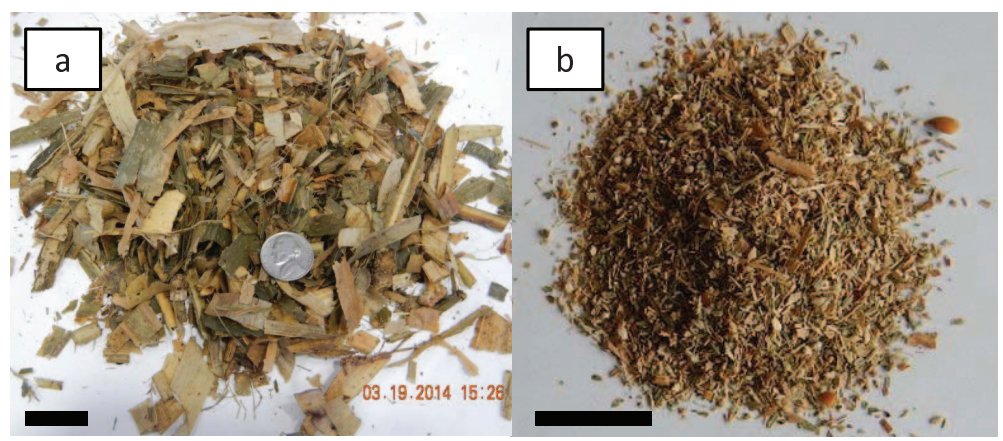

Figure: 4

Author: Klingenberg

Journal: Biomass and Bioenergy 
(a)

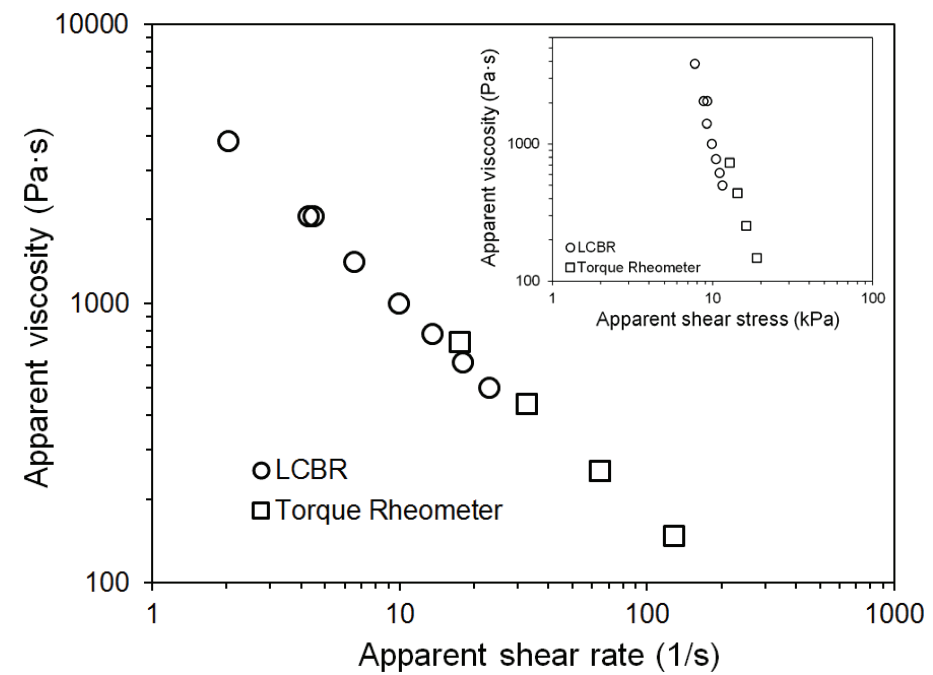

(b)

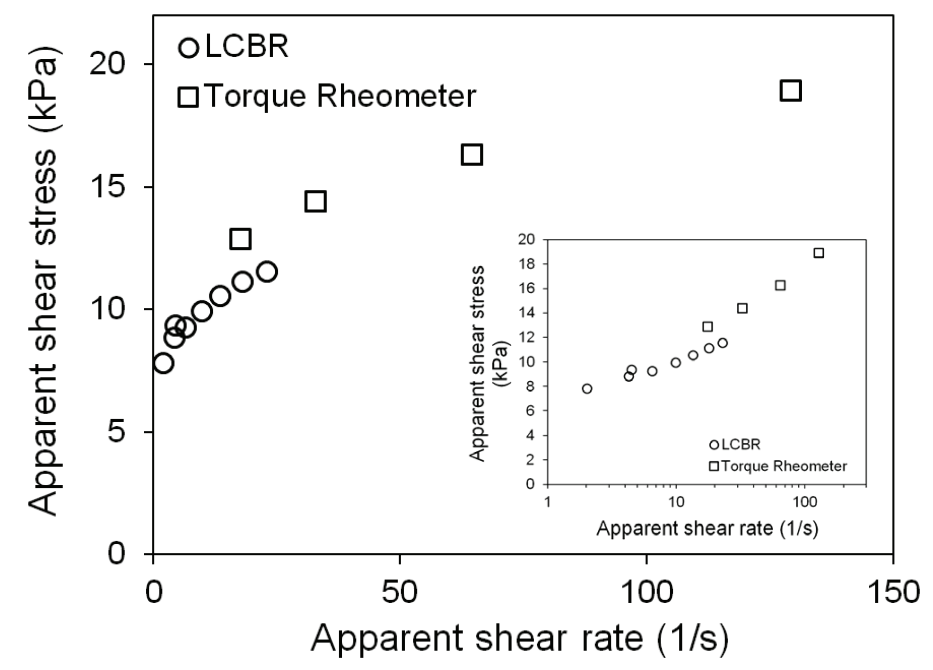

Figure: 5

Author: Klingenberg

Journal: Biomass and Bioenergy 


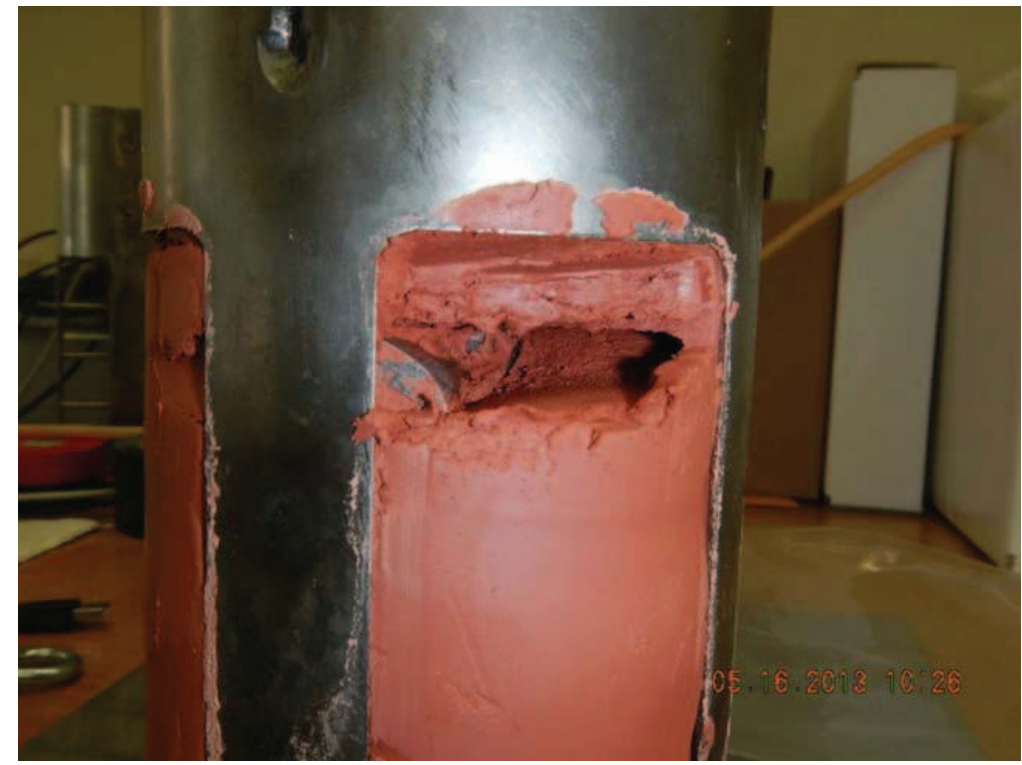

Figure: $\quad 6$

Author: Klingenberg

Journal: Biomass and Bioenergy 
(a)

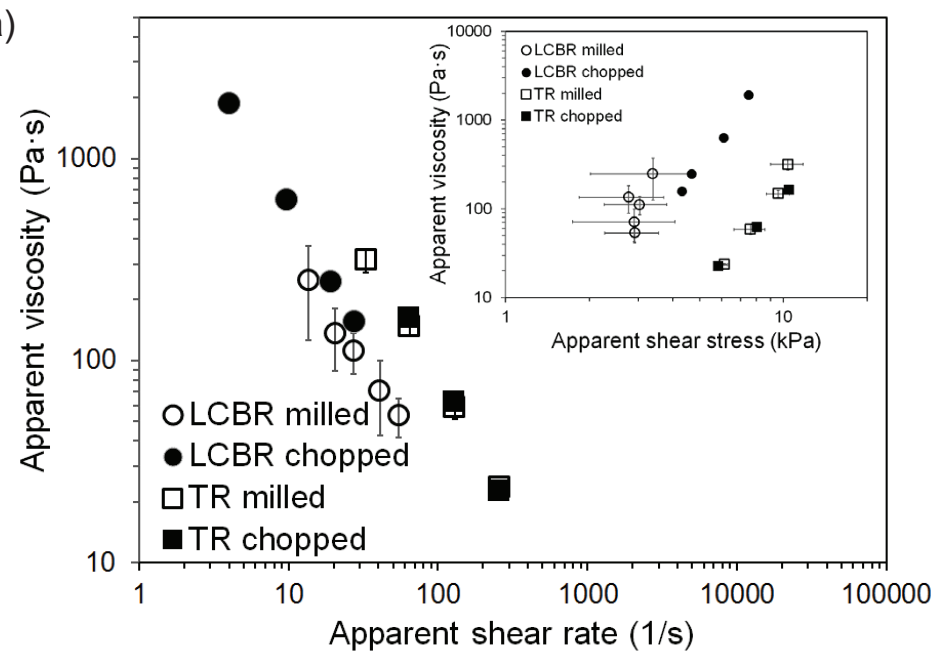

(b)

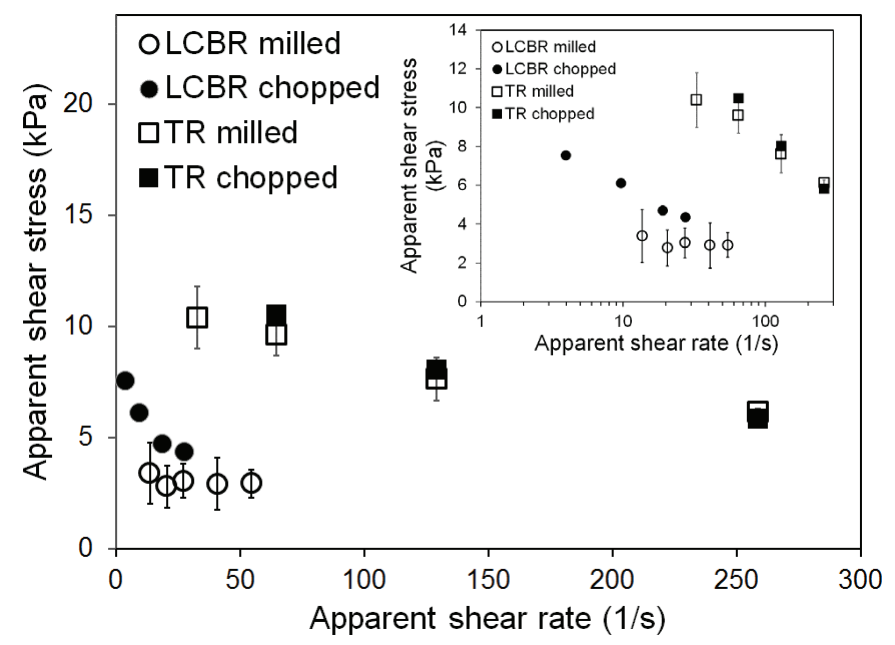

Figure: 7

Author: Klingenberg

Journal: Biomass and Bioenergy 


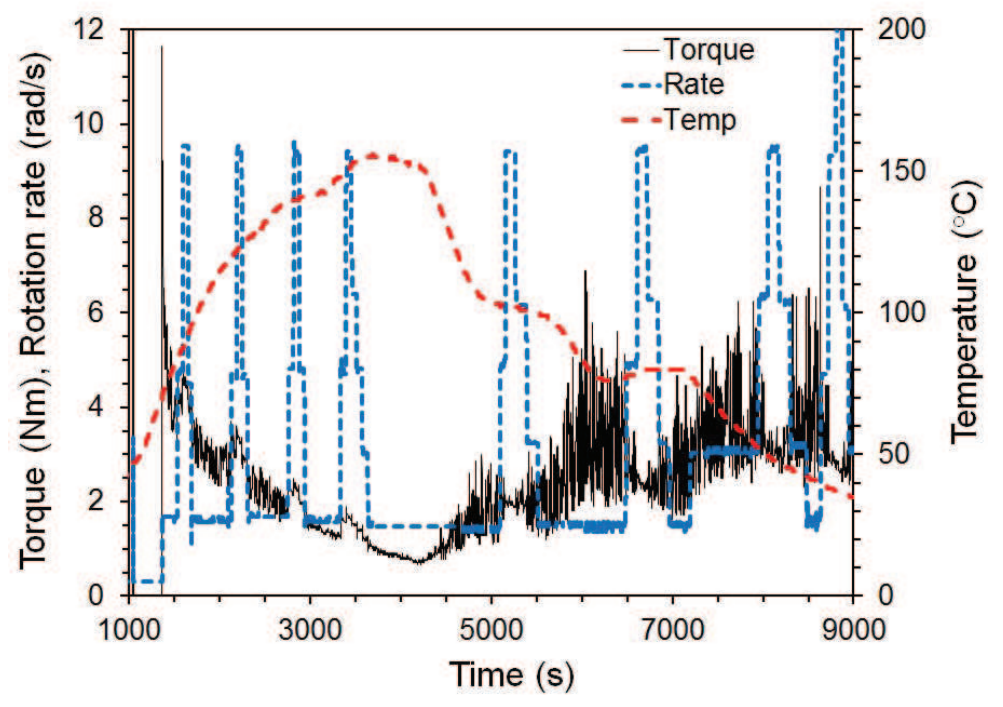

Figure: $\quad 8$

Author: Klingenberg

Journal: Biomass and Bioenergy 
(a)

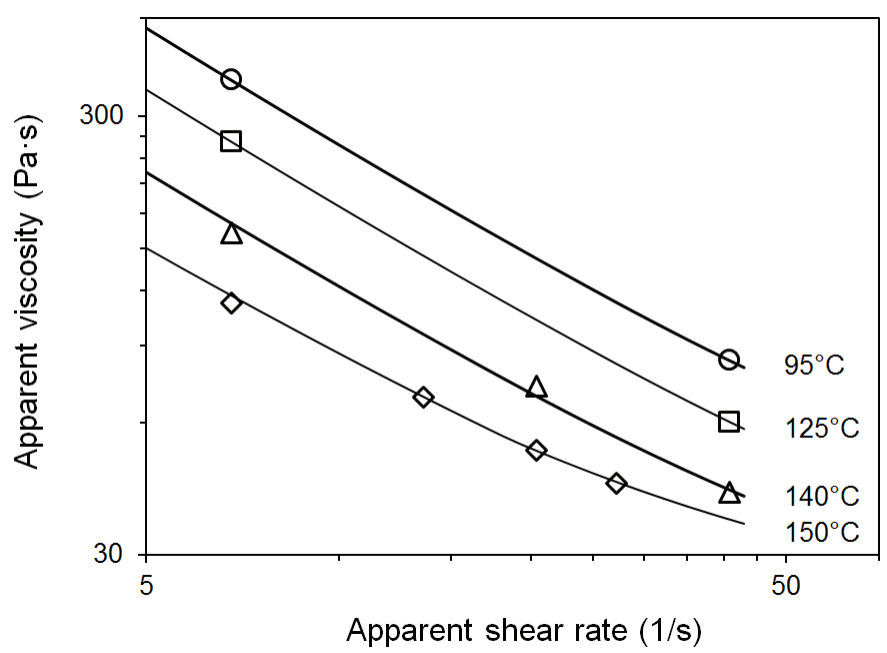

(b)

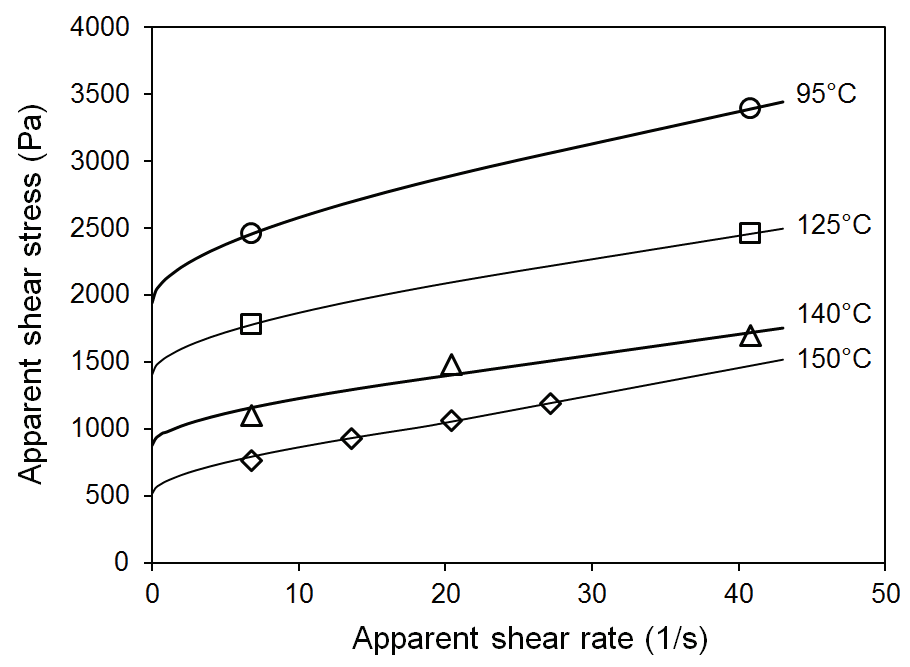

Figure: 9

Author: Klingenberg

Journal: Biomass and Bioenergy 


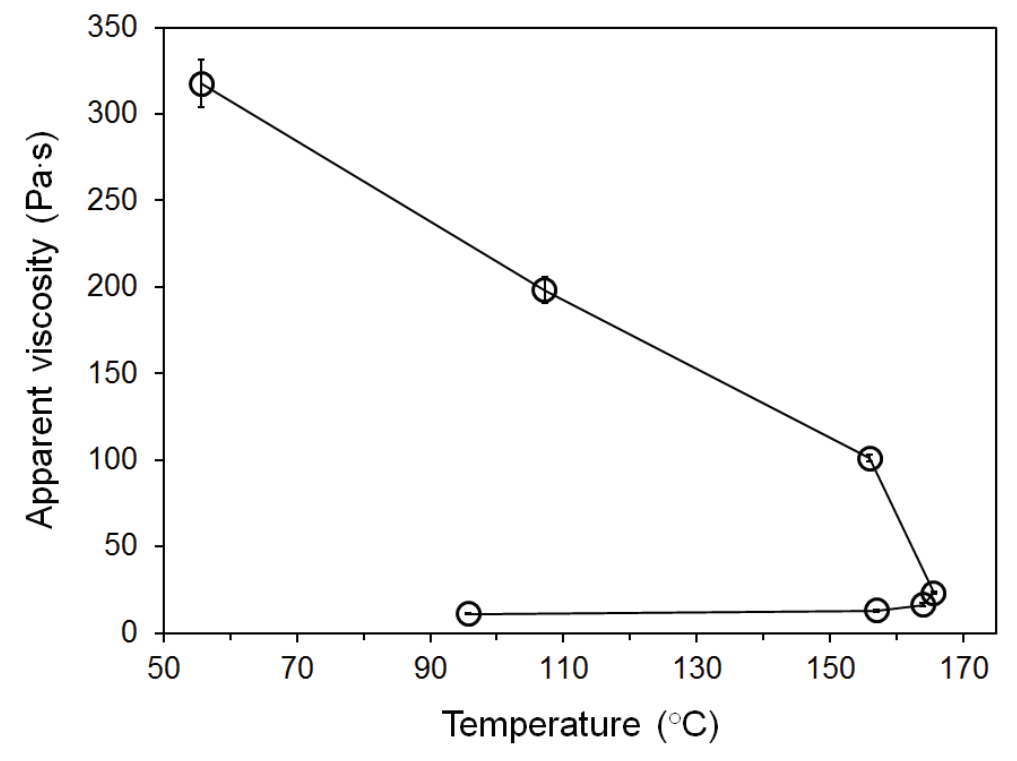

Figure: $\quad 10$

Author: Klingenberg

Journal: Biomass and Bioenergy 